\title{
The aspartic protease napsin A suppresses tumor growth independent of its catalytic activity
}

\author{
Takayuki Ueno ${ }^{1,3}$, Göran Elmberger ${ }^{1}$, Timothy E Weaver², Masakazu Toi ${ }^{3}$ and Stig Linder ${ }^{1}$
}

Members of the aspartic protease family have been implicated in cancer progression. The aspartic protease napsin $A$ is expressed in type II cells of the lung, where it is involved in the processing of surfactant protein B (SP-B). Napsin A is also expressed in kidney, where its function is unknown. Here, we examined napsin A mRNA expression in human kidney tissues using in situ hybridization. Whereas strong napsin A mRNA expression was observed in kidney proximal tubules, expression was detected in only one of 29 renal cell carcinomas. This result is consistent with previous observations of loss of napsin A expression in high-grade lung adenocarcinomas. We re-expressed napsin A in the tumorigenic HEK293 kidney cell line and examined the phenotype of stably transfected cells. Napsin A-expressing HEK293 cells showed an altered phenotype characterized by formation of cyst-like structures in three-dimensional collagen cultures. Napsin A-expressing cells also showed reduced capacity for anchorage-independent growth and formed tumors in SCID mice with a lower efficiency and slower onset compared to vector-transfected control cells. Mutation of one of the aspartic acid residues in the napsin A catalytic site inactivated enzymatic activity, but did not influence the ability to suppress colony formation in soft agar and tumor formation. The mutation of the catalytic site did not affect processing, glycosylation or intracellular localization of napsin A. These data show that napsin A inhibits tumor growth of HEK293 cells by a mechanism independent of its catalytic activity.

Laboratory Investigation (2008) 88, 256-263; doi:10.1038/labinvest.3700718; published online 14 January 2008

KEYWORDS: napsin A; renal cell carcinoma; aspartic protease; tumor suppression

The aspartic protease family includes several physiologically important enzymes such as pepsin, chymosin, renin, gastricsin, cathepsin D and cathepsin E. Some members of this protease family, in particular cathepsin D and cathepsin E, have been implicated in cancer progression. High cathepsin D expression is associated with shorter disease-free and overall survival in patients with breast cancer. ${ }^{1,2}$ In patients with ovarian or endometrial cancer, cathepsin D expression has been reported to be associated with tumor aggressiveness. ${ }^{3,4}$ Transfection of low-metastatic tumor cells with wild-type human cathepsin D results in stimulation of tumor growth and increased propensity for experimental metastasis. ${ }^{5}$ Interestingly, the catalytic activity of cathepsin D is not required for stimulation of tumor growth. ${ }^{6}$ Cathepsin $\mathrm{E}$ expression has been reported to be a prognostic marker in bladder cancer. ${ }^{7}$ Cathepsin $\mathrm{E}$ has also been suggested to promote tumor growth independent of its catalytic activity. ${ }^{8}$

Napsin A is an aspartic protease expressed in the lung and the kidney. ${ }^{9-12}$ Napsin A is expressed in type II cells in lung alveoli and is capable of cleaving the proform of surfactant protein B (SP-B) expressed in this cell type. ${ }^{13,14}$ Studies using siRNA showed that downregulation of napsin-A in type II cells results in inhibition of SP-B processing. ${ }^{13,14}$ Among the different types of lung cancers, only adenocarcinomas express napsin $\mathrm{A}$, making napsin $\mathrm{A}$ a promising diagnostic marker for primary lung adenocarcinomas. ${ }^{15-17}$ Lung adenocarcinomas with a low differentiation grade express napsin A less frequently than more differentiated tumors, suggesting an inverse association between napsin $\mathrm{A}$ and tumor progression. ${ }^{15,16,18}$

Napsin was first described in mouse kidney as a new member of the aspartic protease family (KAP; kidney aspartic protease). ${ }^{9}$ A previous study reported napsin A localization to lysosomes in proximal tubules. ${ }^{19}$ Napsin expression in kidney is first observed at embryonic day 13, preceding kidney tubulogenesis. ${ }^{19}$ The function of napsin in the kidney remains unknown, but the pattern of embryonal expression raises the possibility that napsin may play a role in the

\footnotetext{
${ }^{1}$ Department of Oncology-Pathology, Cancer Center Karolinska, Karolinska Institute and Hospital, Stockholm, Sweden; ${ }^{2}$ Division of Pulmonary Biology, Cincinnati Children's Hospital Medical Center, Cincinnati, OH, USA and ${ }^{3}$ Department of Surgery, Graduate School of Medicine, Kyoto University, Kyoto, Japan

Correspondence: Dr T Ueno, MD, PhD, Department of Surgery, Kyoto University, Kyoto 606-8501, Japan. E-mail: takayuki@kuhp.kyoto-u.ac.jp

Received 14 September 2007; revised 2 December 2007; accepted 2 December 2007
} 
differentiation of proximal tubules. ${ }^{19}$ Considering the importance of lysosomal aspartyl proteases during carcinogenesis and the possible role of napsin during kidney differentiation, here we examined the expression of napsin A in renal carcinomas. Furthermore, we studied the effect of re-expressing napsin A in a tumorigenic kidney cell line. We report that napsin A suppresses anchorage-independent growth and tumor formation by a mechanism independent of its catalytic activity.

\section{MATERIALS AND METHODS In Situ Hybridization}

Twenty-nine renal cell carcinoma tissues, from patients treated in the Karolinska Hospital from 1995 to 1998, were randomly selected. The tissues consisted of 10 grade I, 12 grade II and 7 grade III cancers. The study was approved by the local ethical committee. Formalin-fixed, paraffin-embedded tumor sections were deparaffinized with xylene, treated with proteinase $\mathrm{K}\left(1 \mu \mathrm{g} / \mathrm{ml}, 37^{\circ} \mathrm{C}, 30 \mathrm{~min}\right)$, transferred to $0.1 \mathrm{M}$ triethanolamine buffer $(5 \mathrm{~min})$ and treated with triethanolamine containing $0.25 \%$ acetic anhydride for $10 \mathrm{~min}$. Sections were washed in $2 \times \mathrm{SSC}$, dehydrated and allowed to air-dry. After overnight hybridization $(2 \times$ SSC, $50 \%$ formamide, $10 \%$ dextran sulfate, $55^{\circ} \mathrm{C}$ ) with an ${ }^{35}$ S-labeled RNA probe $\left(1.16 \times 10^{5}\right.$ c.p.m. $\left./ \mu \mathrm{l}\right)$, sections were washed (the most stringent step being $0.1 \times$ SSC, $15 \mathrm{~min}$ at $\left.60^{\circ} \mathrm{C}\right)$ and treated with RNase A $\left(20 \mu \mathrm{g} / \mathrm{ml}, 37^{\circ} \mathrm{C}, 30 \mathrm{~min}\right)$. Finally, the slides were dehydrated, air-dried, dipped in Kodak NTB emulsion, exposed for 7-14 days at $4^{\circ} \mathrm{C}$, developed and counter-stained with hematoxylin-eosin. The probes were made using T3 (antisense) and T7 (sense) RNA polymerase (Promega, Madison, WI, USA) from a pCMSEGFP vector (Clontech, Palo Alto, CA, USA) containing an NheI/EcoRI napsin A full-length cDNA. Both sense and antisense probes were hybridized to all sections.

\section{DNA Constructions}

HA-tagged human napsin A cDNA was generated by polymerase chain reaction (PCR) using specific primers to human napsin A: $5^{\prime}$ primer, agcgctagcatgtctccaccaccgctgct (primer N1); $3^{\prime}$ primer, cgcgaattctcaagcgtagtctgggacgtcg tatgggtacccggggaactgcgcctgcg (primer N2). A PCR fragment was subcloned into pEGFP-N3 vector (Clontech) at NheI and ECoRI site. To generate a mutated napsin cDNA tagged with HA, PCR was performed using specific primers. To generate mutation of the catalytic site, the PCR-based overlap extension method was applied. ${ }^{20}$ Primers were designed as follows: $\mathrm{N}$-terminal fragment, $5^{\prime}$ primer, primer $\mathrm{N} 1$; $3^{\prime}$ primer, ccgtattcaggatggcagcacagccct; C-terminal fragment, $5^{\prime}$ primer, catcctgaatacgggcacgtccctcatc; $3^{\prime}$ primer, primer N2. To generate a control vector, the EGFP sequence was removed from pEGFP-N3 using restriction enzymes SalI and NotI and both ends were filled in using the Klenow fragment, followed by self-ligation. None of the constructs were fused with EGFP. All constructs were subjected to bi-directional sequencing.

\section{Stable Transfectants}

Cells were maintained at $37^{\circ} \mathrm{C}$ in a $7 \% \mathrm{CO}_{2}$ atmosphere in DMEM (Invitrogen, Carlsbad, CA, USA) containing 10\% FBS (Invitrogen). Plasmids were transfected into HEK293 cells using LIPOFECTAMINE (Invitrogen). For stable expression, transfected cells were selected with G418 (Invitrogen) and G418-resistant colonies were analyzed for the expression of wild-type and mutant napsin $\mathrm{A}$ by immunoblotting with anti-HA antibody (clone 3F10; Roche Molecular Biochemicals, Mannheim, Germany).

\section{Western Blotting}

Samples were separated by electrophoresis in $12 \%$ polyacrylamide gel and transferred to nitrocellulose membranes. The membranes were incubated in blocking solution $(5 \%$ nonfat dry milk in PBS containing 0.05\% Tween 20) for $1 \mathrm{~h}$ at room temperature and then incubated overnight with anti-HA antibody (clone 3F10; $100 \mathrm{ng} / \mathrm{ml}$; Roche Molecular Biochemicals) or antibodies directed against mature SP-B (number 28031) or SP-B proprotein (number 55522). ${ }^{21}$ The membranes were washed and incubated with horseradish peroxidase (HRP)-conjugated anti-rat IgG (Pierce, Rockford, IL, USA) or HRP-conjugated anti-rabbit Ig (Amersham Biosciences, Little Chalfont, UK) for $1 \mathrm{~h}$. The membranes were washed six times and peroxidase activity was developed by SuperSignal West Pico (Pierce) according to the manufacturer's instructions.

\section{Cell Proliferation Assay}

For each cell line, $1 \times 10^{4}$ cells were seeded in 5 wells $\times 5$ rows of 96-well plates in $100 \mu \mathrm{l}$ DMEM containing 10\% FBS. After 24, 48, 72 and $96 \mathrm{~h}$, cell proliferation was assayed using CellTiter $96^{\circledR}$ Non-Radioactive Cell Proliferation Assay (Promega) according to the manufacturer's instructions. After growth curves were drawn, cell doubling time was calculated using the log-phase growth rate: cell doubling time $=(2 /$ the log phase growth rate for $24 \mathrm{~h}) \times 24 \mathrm{~h}$.

\section{Colony Formation in Soft Agar}

Five hundred cells from each of the stably transfected cell lines were suspended in $2.5 \mathrm{ml}$ of $0.35 \%(\mathrm{~W} / \mathrm{V})$ agar in DMEM/20\% FBS and overlaid onto $0.5 \mathrm{ml}$ of $0.5 \%$ (W/V) agar in DMEM $/ 20 \%$ FBS in three wells of a 12 -well plate. After 10 days, colonies with more than 20 cells were scored as positive using an inverted microscope.

\section{Cell Culture in Collagen Gel}

Five hundred cells were suspended in $1.5 \mathrm{ml}$ of type I collagen gel solution containing 66\% vitrogen 100 (Cohesion Technologies, Palo Alto, CA, USA), $1 \times$ DMEM, $0.004 \mathrm{~g} / \mathrm{l}$ folic acid and $3.7 \mathrm{~g} / \mathrm{l}$ sodium bicarbonate and overlaid onto $0.6 \mathrm{ml}$ of collagen gel solution in a 12 -well plate.

\section{Tumor Growth in SCID Mice}

Cells from each clone were suspended in PBS $\left(2 \times 10^{7}\right.$ cells/ $\mathrm{ml}$ ) and injected subcutaneously at the right and left 
dorsal flanks of C.B-17/IcrCrl SCID mice (Charles River Laboratories, Sulzfeld, Germany) (100 $\mu$ l per mouse). Five mice were injected with each clone. The tumor volume was measured daily until day 141 with a caliper rule. The tumors' major and minor diameters were measured and the volume was estimated at $4 / 3 \pi \times$ (major radius $) \times(\text { minor radius })^{2}$. Mice were killed when the major diameter of the tumor had reached $2 \mathrm{~cm}$. In all the experiments, the ethical guidelines for investigations in conscious animals were followed and the experiments were approved by the local Ethics Committee for Animal Research.

\section{Deglycosylation}

Cells were lysed in a denaturing buffer (PBS, $0.5 \%$ SDS, $1 \%$ $\beta$-mercaptoethanol) and boiled for $10 \mathrm{~min}$. The supernatant was incubated for $1 \mathrm{~h}$ with endoglycosidases $\mathrm{F}$ (New England Biolabs, Beverly, MA, USA) as recommended by the manufacturer.

\section{Immunoprecipitation}

Cells were lysed in a lysis buffer (PBS, $20 \mathrm{mM}$ EDTA, $1 \mathrm{mM}$ PMSF, 1\% Elugent (Calbiochem, Darmstadt, Germany)) at $4^{\circ} \mathrm{C}$ for $30 \mathrm{~min}$ and centrifuged at $12000 \mathrm{~g}$ at $4^{\circ} \mathrm{C}$ for $20 \mathrm{~min}$. The supernatant was incubated with anti-HA affinity matrix (Roche Molecular Biochemicals) at $4^{\circ} \mathrm{C}$ overnight and the matrix was washed with the lysis buffer six times.

\section{Proteolytic Activity of Napsin A}

Recombinant proSP-B lacking the entire 102 amino-acid C-terminal domain $\left(\mathrm{SP}-\mathrm{B}_{\Delta \mathrm{C}}\right.$ ) was synthesized in the baculovirus system. The sequence encoding residues 1-279 of the human SP-B proprotein $\left(\mathrm{SP}_{-} \mathrm{B}_{\Delta \mathrm{C}}\right)$ was cloned in-frame with a six-residue C-terminal histidine tag and ligated into pVL1393 (BD Biosciences Pharmingen, San Diego, CA, USA). Recombinant baculovirus was produced by homologous recombination in Spodoptera frugiperda cells, as previously described. ${ }^{22}$ Fresh monolayers of Trichoplusia ni cells were infected with plaque purified recombinant virus at an MOI of 2 and cultured in serum-free media for $72 \mathrm{~h}$. Recombinant $\mathrm{SP}-\mathrm{B}_{\Delta \mathrm{C}}$ was purified from the culture media of infected insect cells by NTA affinity chromatography, under non-denaturing conditions, as previously described. ${ }^{23}$ Purified $S P-B_{\Delta C}$ was incubated with immunoprecipitates from the stable transfectants of control, napsin A or either mutant in an incubation buffer $(0.1 \mathrm{M}$ sodium acetate, $20 \mathrm{mM}$ EDTA, $\mathrm{pH} 4.7)$ at $37^{\circ} \mathrm{C}$ for $2 \mathrm{~h}$.

\section{Immunofluorescence}

Cells grown on coverslips were fixed $(4.0 \%$ formaldehyde in PBS, pH 7.4, $10 \mathrm{~min})$, permeabilized $(0.1 \%$ Triton X-100 in PBS, $3 \mathrm{~min}$ ) and blocked for $30 \mathrm{~min}$ in medium containing $5 \%$ normal goat serum. After rinsing with PBS, immunostaining was performed by incubating the cells with antibodies in the following order with rinsing between antibodies: anti-HA (2 ng/ $\mu \mathrm{l}$; clone 3F10; Roche Molecular
Biochemicals), Cy3-conjugated anti-rat IgG $(\mathrm{H}+\mathrm{L})(1: 100$; Jackson ImmunoResearch, West Grove, PA, USA), antiLAMP-1 (1:200; BD Biosciences, Palo Alto, CA, USA) and fluorescein-conjugated anti-mouse IgG heavy and light chain (1:30; Calbiochem). Coverslips were mounted onto slides with VECTASHIELD Mounting medium with DAPI (H-1200, Vector Laboratories Inc., Burlingame, CA, USA). Cells were visualized by an immunofluorescence microscope (Axioplan 2 imaging, ZEISS). Cells in collagen gels were stained after digestion of collagen with $100 \mathrm{U} / \mathrm{ml}$ collagenase (Sigma-Aldrich Sweden AB, Stockholm, Sweden) for $15 \mathrm{~min}$. Cells were fixed (4.0\% formaldehyde in PBS, $\mathrm{pH} 7.4,15 \mathrm{~min}$ ), permeabilized $(0.5 \%$ Triton $\mathrm{X}-100$ in PBS, $15 \mathrm{~min})$, incubated $(0.5 \mathrm{mg} / \mathrm{ml}$ sodium borohydrate in PBS) and blocked for $30 \mathrm{~min}$ in medium containing 5\% normal goat serum. After rinsing with PBS, immunostaining was performed as above.

\section{RESULTS \\ Lack of Napsin A mRNA Expression in Renal Cell Carcinoma}

Napsin A mRNA expression was examined in normal and cancerous kidney tissue using in situ hybridization (Figure 1). In normal kidney tissue, napsin A mRNA expression was observed in proximal convoluted and straight tubules and collecting ducts in agreement with previous reports (Figure $1 \mathrm{a}$ and b). ${ }^{12,19}$ Twenty-nine renal carcinomas were
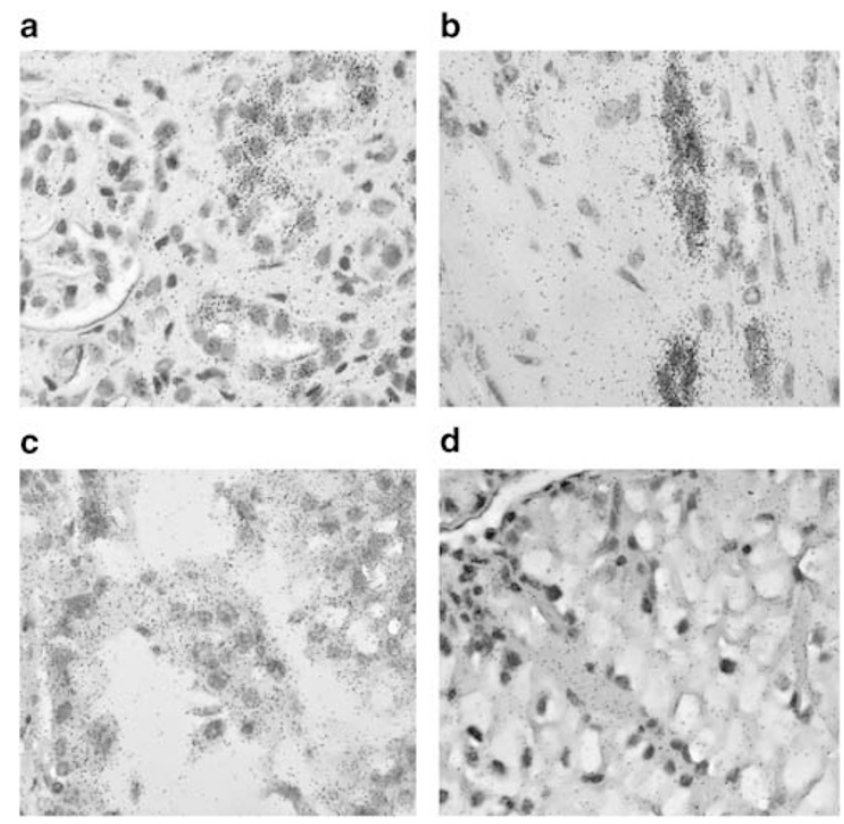

Figure 1 Analysis of napsin A mRNA expression in kidney tissues by in situ hybridization. In normal parts of the kidney, proximal convoluted tubules (a), proximal straight tubules and collecting ducts (b) showed napsin A expression. One positive case of renal cell carcinoma, which expressed napsin A mRNA (a grade II tumor), is shown (c). The majority of renal carcinomas studied did not express napsin A mRNA (d). Magnification $\times 40$. 
examined (10 grade I, 12 grade II and 7 grade III tumors). Only one of these tumors (a grade II tumor) showed detectable napsin A mRNA expression (Figure 1c), whereas the remaining 28 renal cell carcinomas examined did not show napsin A signals above background (Figure 1d).

\section{Generation and Characterization of Cells Expressing Wild-Type and Catalytically Defective Napsin A}

The observation of downregulation of napsin A in kidney tumors prompted us to generate kidney tumor cells that stably express napsin A. HEK293 is a tumorigenic cell line originally derived from human embryonic kidney cells by transfection of adenovirus type 5 DNA. ${ }^{24}$ This cell line does not express a detectable amount of napsin A. ${ }^{12}$ An HA-tagged cDNA napsin A construct (Figure 2a) was generated and transfected into HEK293 cells. Three clones that were stably expressing napsin A (napsin 1, napsin 2 and napsin 3) were isolated, together with two clones transfected with empty vector as a control. We also generated a mutation in the catalytic site by changing Asp283 into an Asn (napsin ${ }^{\text {D283N }}$ ) (Figure 2a). The mutant was transfected into HEK293 cells and clones stably expressing the mutant were selected (clones napsin ${ }^{\mathrm{D} 283 \mathrm{~N}} 21$ and napsin ${ }^{\mathrm{D} 283 \mathrm{~N}} 22$ ). The level of expression of wild-type and mutated napsin A was comparable in these clones (Figure 2b). Napsin A expression was also analyzed by immunofluoresence staining and we found $>99 \%$ of the cells to stain positive. Cells expressing the mutant had similar population doubling times as napsin A transfectants and significantly $(P<0.001)$ longer time than control cells $(25.3 \pm 1.3$ and $24.9 \pm 1.5 \mathrm{~h}$ for control 1 and $2 ; 29.2 \pm 0.4$ and $27.2 \pm 1.6 \mathrm{~h}$ for napsin 1 and $2 ; 29.4 \pm 3.5$ and $31.4 \pm 1.2 \mathrm{~h}$ for napsin ${ }^{\mathrm{D} 283 \mathrm{~N}} 21$ and 22).
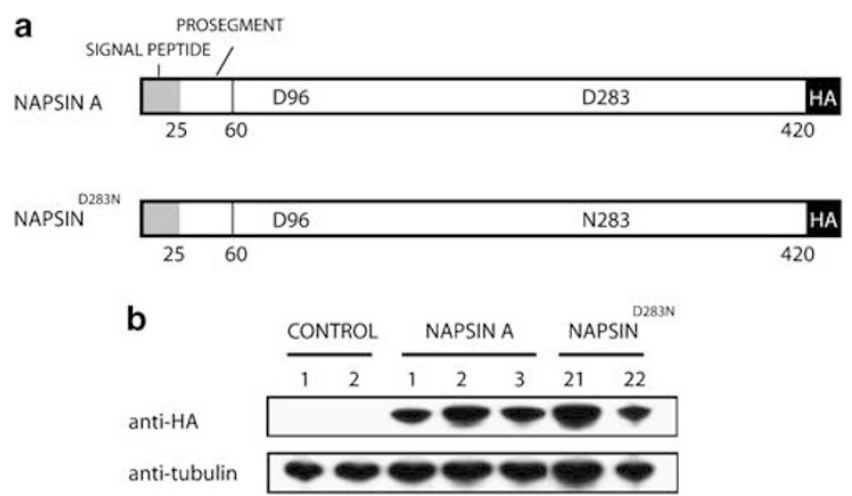

Figure 2 (a) Structures of wild-type and mutant napsin A cDNA constructs. The first amino acid (Met) predicted from the full CDNA sequence is numbered as 1 . Deduction of the initial residue of mature protein is based on the result by Schauer-Vukasinovic et $a^{25} .^{25}$ In napsin ${ }^{D 283 N}$, Asp $^{283}$ in the catalytic site was changed to an Asn by site-directed mutagenesis. Napsin cDNA constructs have HA tags in their C-termini. (b) Protein expression levels of each clone. Clones that express napsin A or the catalytically inactive napsin ${ }^{\mathrm{D} 283 \mathrm{~N}}$ protein were analyzed together with control clones transfected with empty vector. The expression level is shown by western blotting using an anti-HA antibody with tubulin as control.
We examined whether the D283N mutation resulted in loss of catalytic activity and whether the mutation altered the processing and intracellular localization of the enzyme. The $\mathrm{N}$-terminal propeptide of proSP-B has been reported to be a physiological substrate of napsin A. ${ }^{16}$ Mutation of the catalytic aspartic acid residue D283 resulted in loss of the ability of napsin to cleave a truncated form of recombinant proSP-B $\left(\mathrm{SP}-\mathrm{B}_{\Delta \mathrm{C}}\right)$ (Figure $3 \mathrm{a}$ ). Napsin $\mathrm{A}$ is synthesized in a proform and processed into the mature form by removal of its $\mathrm{N}$-terminal prosegment. The mature protein is glycosylated in some or all of the three potential N-linked oligosaccharide attachment sites. ${ }^{25}$ Wild-type napsin A and napsin ${ }^{\mathrm{D} 283 \mathrm{~N}}$ both migrated as $41 \mathrm{kDa}$ proteins in SDS-PAGE (Figure 3b). Deglycosylation by endoglycosidase $\mathrm{F}$ resulted in a decrease in the molecular weight to $38 \mathrm{kDa}$ (Figure $3 \mathrm{~b}$ ), in agreement with the estimated molecular weight $(38.9 \mathrm{kDa})$ of mature napsin A. These results suggest that wild-type and mutant napsins were glycosylated in the same way. As inactivation of the catalytic site did not affect processing, maturation of napsin $\mathrm{A}$ is not dependent on intramolecular autocatalysis in HEK293 cells.

Finally, to examine if the D293N mutation affects the intracellular localization of napsin A, we generated an expression vector expressing wild-type napsin A fused with GFP. This vector was transfected into cells expressing either wildtype or mutated napsin A containing an HA tag. As shown in Figure 3c, mutated napsin A (stained with a Cy3-labeled antibody) colocalized with wild-type napsin A (GFP), suggesting that mutation in the catalytic site did not affect the localization of napsin A.

\section{Napsin A Expression Leads to Tube Formation and Reduced Colony Formation in Soft Agar Independent of Its Catalytic Activity}

The phenotype of the HEK293 cell clones expressing wildtype or mutant napsin A was examined in detail. The cells of different clones were grown in collagen gels for 2 weeks. Phase-contrast microscopy showed that napsin A-transfected cells formed tube-like structures with branching morphology in the collagen gels whereas control cells did not (Figure 4a). Cells expressing napsin ${ }^{\mathrm{D} 283 \mathrm{~N}}$ also formed tube-like structures in collagen (not shown). The difference in the organization of the cells in the collagen gels was more clearly discerned after DAPI staining of cell nuclei (Figure $4 \mathrm{~b}$ ). Napsin A-expressing cells formed cyst-like structures whereas control cells did not (Figure $4 \mathrm{~b}$ and $\mathrm{c}$ ). Interestingly, napsin A staining was observed in the center of the cyst-like structures (Figure 4c). These results suggest that napsin A promotes differentiation of HEK293 cells.

To determine whether the change in phenotype was associated with an altered ability for anchorage-independent growth, the ability of these cell lines to form colonies in soft agar was determined. All three clones of napsin A-expressing cells formed fewer colonies in soft agar than control clones (Figure 5). Cells expressing napsin ${ }^{\mathrm{D} 283 \mathrm{~N}}$ formed a similar 
a

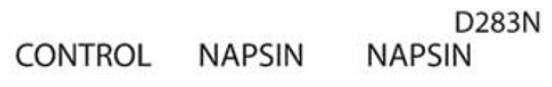

$28 \mathrm{kDa}$

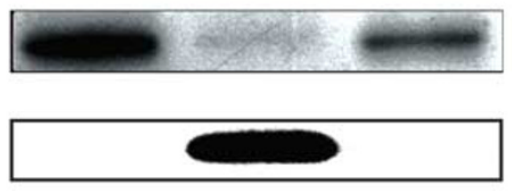

b

$12 \mathrm{kDa}$

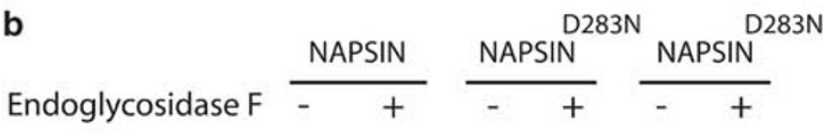

$49 \mathrm{kDa}$

$38 \mathrm{kDa}$

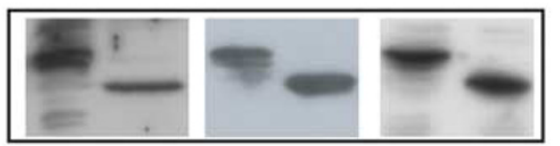

C

WT-NAPSIN-GFP $+$ WT-NAPSIN-HA

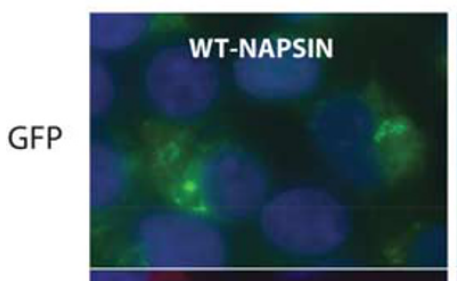

WT-NAPSIN

$\mathrm{Cy} 3$

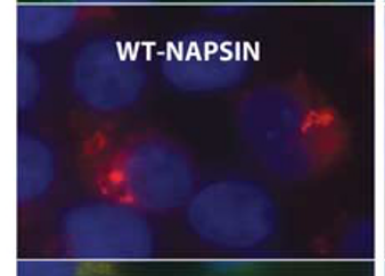

WT-NAPSIN + WT-NAPSIN

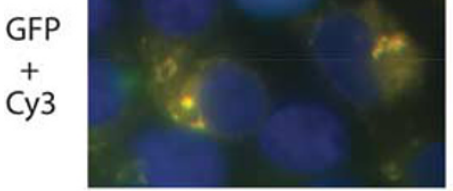

Figure 3 Functional analysis of wild-type and mutated napsin A proteins. (a) Recombinant $\mathrm{SP}-\mathrm{B}_{\Delta \mathrm{C}}$ was synthesized in the baculovirus system, and napsin $A$ and its mutant were expressed in HEK293 cells. Recombinant SP-B $\mathrm{B}_{\triangle \mathrm{C}}$ was incubated with napsin $\mathrm{A}$ or its mutant at $\mathrm{pH} 4.7$ at $37^{\circ} \mathrm{C}$ for $2 \mathrm{~h}$. Napsin A cleaved SP-B $B_{\Delta C}$ whereas napsin ${ }^{D 283 \mathrm{~N}}$ had lost the catalytic activity. (b) Deglycosylation of wild-type and mutated napsin A proteins. Napsin $\mathrm{A}$ and Napsin ${ }^{\mathrm{D} 283 \mathrm{~N}}$ migrated as $41 \mathrm{kDa}$ proteins and both these proteins migrated as $38 \mathrm{kDa}$ proteins after deglycosylation by endoglycosidase F. Stable HEK293 clones expressing napsin A were analyzed; napsin-1 (expressing wild-type napsin) and clones napsin ${ }^{\mathrm{D} 283 \mathrm{~N}} 21$ and napsin ${ }^{\mathrm{D} 283 \mathrm{~N}} 22$ (expressing catalytically inactive napsin A). (c) Colocalization of wild-type and mutant napsin A proteins. A vector for wild-type napsin A fused with GFP was transfected into cells expressing HA-tagged napsin A or the napsin ${ }^{\mathrm{D} 283 \mathrm{~N}}$ mutant. HA-tagged napsin A and the D283N mutant were visualized with Cy3-labeled anti-HA antibody (red). Wild-type napsin A fused with GFP (green) was colocalized with napsin ${ }^{\text {D283N }}$ with HA tag (red) (lower panel). a

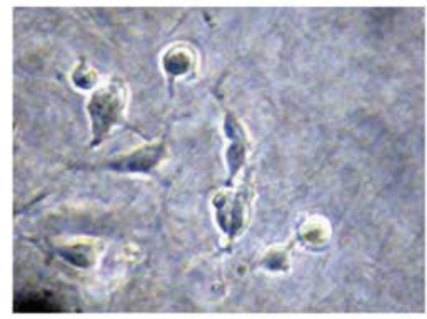

b

HEK293-NAPSIN-1

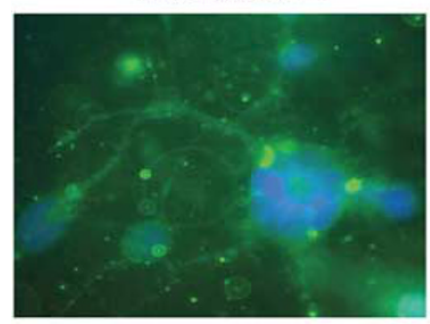

C

HEK293-CLONE 1
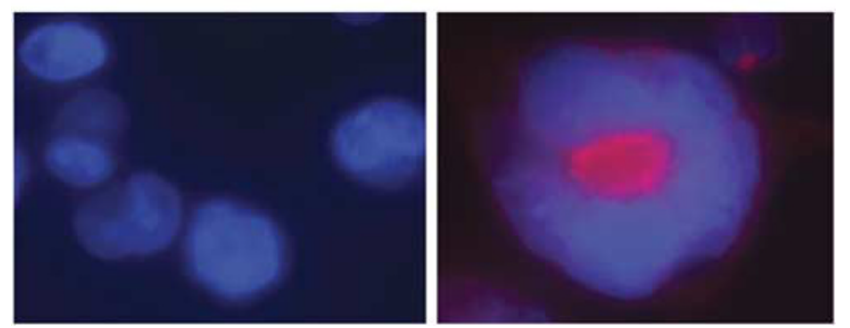

Figure 4 Cyst and branch formation by napsin A-expressing cells. HEK293 cells expressing napsin $A$ and vector-transfected cells were grown in threedimensional collagen gels for 14 days. $(\mathbf{a}, \mathbf{b})$ Effect of napsin $A$ on cell morphology. (a) Phase-contrast photographs of HEK293 cells in collagen gels. Note that napsin A-expressing cells formed a tube-like structure with branching morphology whereas control cells did not. (b) HEK293 cells in collagen gels visualized by fluorescence microscopy. Cell nuclei were stained with DAPI (blue) and cytoplasms were visualized by immunostaining for LAMP-1. (c) Staining of napsin A in cells forming cysts. HEK293 cells in collagen gels were visualized by fluorescence microscopy. Cell nuclei were stained with DAPI (blue) and napsin A was visualized by immunostaining (red). Napsin A was expressed within the central portions of the cysts.

number of colonies as cells expressing wild-type napsin, and fewer than control (Figure 5). The catalytic activity of napsin A therefore does not appear to be required for suppression of colony formation in soft agar.

\section{Tumor Growth In Vivo}

Tumor formation of cells expressing wild-type or mutated napsin A was examined in SCID mice. Injection of HEK293 cells transfected with empty vector resulted in tumors first detected between days 30 and 36 (Figure 6). All injections resulted in tumor formation. The wild-type napsin A-expressing clones formed tumors with delayed onsets (day 70 to day 133). Six injections out of 10 in this group (2 from napsin 1 and 4 from napsin 2) did not result in detectable 


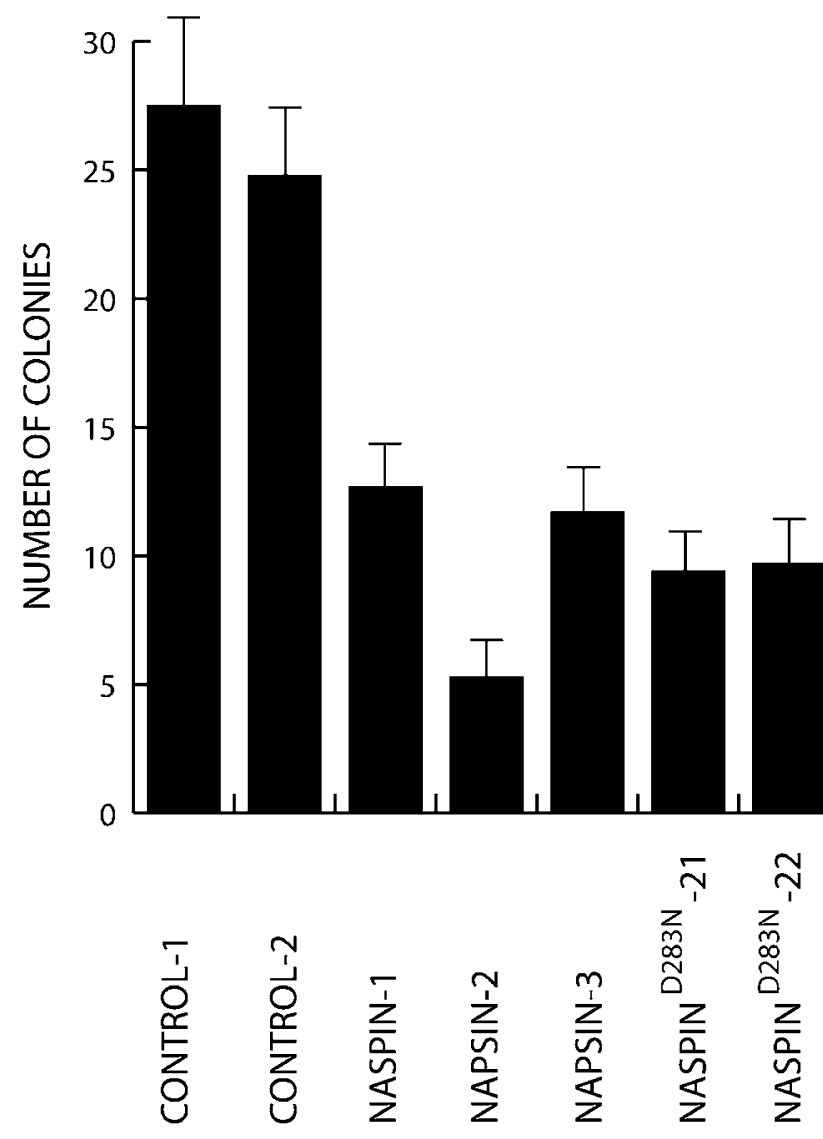

Figure 5 Inhibition of anchorage-independent growth of HEK293 cells by napsin A. Five hundred cells of each clone were suspended in $0.35 \%$ soft agar in three replica wells of 12-well plates. After 10 days, colonies with more than 20 cells were counted. All three clones stably transfected with napsin A formed fewer colonies in soft agar than the control cells transfected with vector alone. Both clones expressing napsin ${ }^{\mathrm{D} 283 \mathrm{~N}}$ formed soft agar colonies with a similar efficiency as cells expressing wild-type napsin A. tumors during the observation period (141 days). Similarly, the napsin ${ }^{\mathrm{D} 23 \mathrm{~N}}$-expressing clones formed tumors with delayed onsets (onset: day 46 to day 102). Five injections out of 10 ( 3 from napsin ${ }^{\mathrm{D} 283 \mathrm{~N}} 21$ and 2 from napsin ${ }^{\mathrm{D} 283 \mathrm{~N}} 22$ ) did not form tumors during the observation period. These data show that expression of wild-type napsin A and catalytically defective napsin A delayed tumor formation of HEK293 cells in SCID mice.

\section{DISCUSSION}

Napsin mRNA expression is detected in mesonephric tubules of the mouse kidney at embryonic day $13 .{ }^{19}$ Expression is observed in proximal convoluted tubules in the mouse ${ }^{19}$ and human (this study). Despite the fact that renal cell carcinomas arise mostly from proximal convoluted tubules, ${ }^{26}$ napsin A mRNA was detected only in one of 29 cases of renal cell carcinoma. This result is consistent with a previous report where no staining of napsin A was observed in 15 cases of renal cell carcinoma by immunohistochemistry. ${ }^{15} \mathrm{~A}$ similar pattern of napsin expression during embryogenesis and carcinogenesis is observed in the lung. Napsin expression is detected at the onset of differentiation of type II cells at embryonic day $15^{19}$ and is maintained in type II cells in the adult. ${ }^{11,12}$ Napsin A is expressed in well-differentiated lung adenocarcinomas, whereas expression is weak in poorly differentiated tumors. ${ }^{15,16}$

Napsin A has no known role in kidney. The pattern of napsin A expression during development and carcinogenesis raises the possibility that napsin A may have a function in inducing and/or maintaining the differentiated state. We engineered HEK293 kidney cells to express napsin A cDNA. Napsin A is strongly expressed in normal kidney and lung tissue; in the lung, napsin A was originally identified as a strong spot (TA02) on two-dimensional gels ${ }^{27}$ and kidney

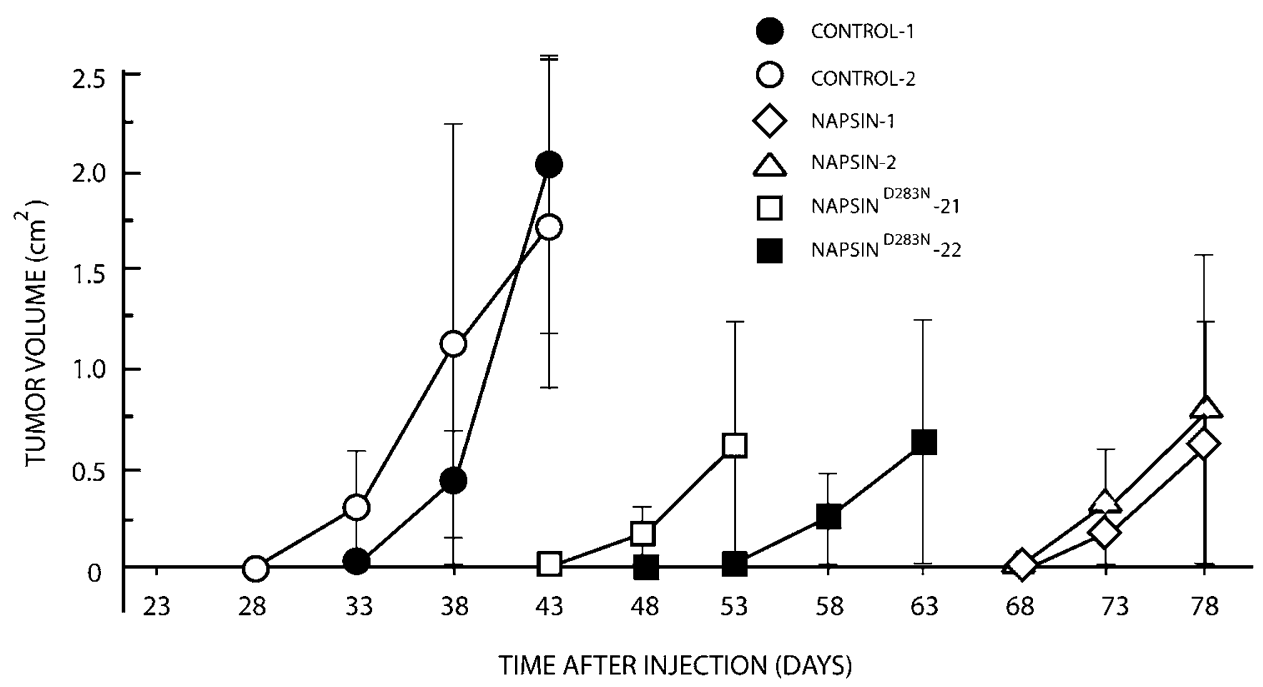

Figure 6 Tumor growth of HEK293 cells in SCID mice. SCID mice were subcutaneously injected with $2 \times 10^{6}$ cells at the dorsal flank. Each group consisted of five mice. Data are mean \pm s.e.m. Cells expressing wild-type napsin A and napsin ${ }^{\mathrm{D} 283 \mathrm{~N}}$ showed reduced growth of tumors compared with control cells. Animals with large tumors were killed in accordance with local ethical committee regulations. 
expression has also been reported to be strong. ${ }^{10}$ We were therefore not concerned that stably transfected cells would express unphysiological levels of the protein. Napsin A-transfected HEK293 cells had somewhat (10-20\%) longer population doubling times compared with vector-transfected cells. Interestingly, when napsin A-expressing cells were grown in three-dimensional collagen gels, they were found to form cyst-like structures. Induction of this phenotype was not dependent on the catalytic activity of napsin A. Although the mechanism(s) involved is presently unknown, this result suggests that napsin A may have a function in the differentiation of kidney epithelial cells.

Napsin A-expressing HEK293 cells showed a reduced capacity for anchorage-independent growth. Furthermore, napsin A-expressing cells formed tumors in SCID mice with a lower efficiency and with a delayed onset. This finding is consistent with an association of napsin A in maintaining a higher degree of differentiation of kidney epithelial cells. The inhibition of anchorage-independent growth and tumor formation was found to be independent of the catalytic activity of napsin.

Previous studies have implicated aspartic proteases in tumorigenesis. Cathepsin D has been shown to stimulate cancer growth in vitro and in vivo. ${ }^{28,29}$ Downregulation of cathepsin $D$ by antisense methods leads to decreased tumorigenicity of breast cancer cells in nude mice. ${ }^{30}$ Interestingly, a mutated cathepsin D lacking its catalytic activity stimulates cancer cell proliferation as efficiently as the wild type. ${ }^{6}$ It has been hypothesized that stimulation of cancer growth by cathepsin $\mathrm{D}$ is mediated by an as yet unknown receptor. ${ }^{6}$ As the overall structure of napsin A is similar to that of cathepsin D, one possible mechanism of tumor suppression by napsin $\mathrm{A}$ is that napsin A may antagonize the growth stimulatory effect of a hypothetical cathepsin $\mathrm{D}$ receptor.

The localization of the catalytic mutant was found to be indistinguishable from that of wild-type napsin A. Furthermore, the mutant enzyme was processed and glycosylated in the same way as wild-type napsin A. Different activation mechanisms have been described for aspartic proteases, including autoactivation (pepsinogen ${ }^{31}$ ), activation in trans by other enzyme(s) (prorenin ${ }^{32}$ ) and a combination of autoactivation and assisted cleavage (procathepsin $\mathrm{D}^{33}$ ). A previous study showed that purified napsin A does not cleave a 15-amino-acid peptide covering its own propeptide cleavage site. ${ }^{25}$ This suggested that napsin $\mathrm{A}$ is not activated by autoactivation. Our data directly show that processing of napsin A is not dependent on intramolecular autocatalysis, at least not in HEK293 cells.

In conclusion, we showed that napsin A suppressed tumor growth in HEK293 cells independent of its catalytic activity. Further insight into the mechanim(s) involved may help in defining targets for therapeutic intervention in renal cancer. One possible strategy would be to reintroduce napsin A into cells. Other strategies could involve design of drugs or other agents that mimic the activity of napsin A. It is important to further elucidate the mechanisms of tumor suppression by napsin A to better understand the biology of kidney cancer development.

\section{ACKNOWLEDGEMENT}

We thank Vivianne Eklund for technical assistance and Kicki Edwardsson and Cecilia Broddling for assistance with mouse experiments. This study was supported by grant from Cancerfonden, Gustav V Jubilee Foundation, Cancerföreningen in Stockholm and Vetenskapsrådet.

1. Rochefort H, Garcia M, Glondu M, et al. Cathepsin D in breast cancer: mechanisms and clinical applications, a 1999 overview. Clin Chim Acta 2000;291:157-170.

2. Foekens JA, Look MP, Bolt-de Vries J, et al. Cathepsin-D in primary breast cancer: prognostic evaluation involving 2810 patients. $\mathrm{Br} \mathrm{J}$ Cancer 1999;79:300-307.

3. Scambia G, Panici PB, Ferrandina G, et al. Clinical significance of cathepsin D in primary ovarian cancer. Eur J Cancer 1994;30A:935-940.

4. Nazeer T, Church K, Amato C, et al. Comparative quantitative immunohistochemical and immunoradiometric determinations of cathepsin $D$ in endometrial adenocarcinoma: predictors of tumor aggressiveness. Mod Pathol 1994;7:469-474.

5. Liaudet E, Garcia M, Rochefort H. Cathepsin D maturation and its stimulatory effect on metastasis are prevented by addition of KDEL retention signal. Oncogene 1994;9:1145-1154.

6. Glondu M, Coopman P, Laurent-Matha V, et al. A mutated cathepsin-D devoid of its catalytic activity stimulates the growth of cancer cells. Oncogene 2001;20:6920-6929.

7. Wild PJ, Herr A, Wissmann C, et al. Gene expression profiling of progressive papillary noninvasive carcinomas of the urinary bladder. Clin Cancer Res 2005;11:4415-4429.

8. Tatnell PJ, Cook M, Kay J. An alternatively spliced variant of cathepsin E in human gastric adenocarcinoma cells. Biochim Biophys Acta 2003;1625:203-206.

9. Mori K, Ogawa $\mathrm{Y}$, Tamura N, et al. Molecular cloning of a novel mouse aspartic protease-like protein that is expressed abundantly in the kidney. FEBS Lett 1997;401:218-222.

10. Tatnell PJ, Powell DJ, Hill J, et al. Napsins: new human aspartic proteinases. Distinction between two closely related genes. FEBS Lett 1998;441:43-48.

11. Chuman $Y$, Bergman $A$, Ueno $T$, et al. Napsin $A$, a member of the aspartic protease family, is abundantly expressed in normal lung and kidney tissue and is expressed in lung adenocarcinomas. FEBS Lett 1999;462:129-134.

12. Schauer-Vukasinovic $V$, Bur $D$, Kling $D$, et al. Human napsin $A$ : expression, immunochemical detection, and tissue localization. FEBS Lett 1999;462:135-139.

13. Brasch $F$, Ochs $M$, Kahne $T$, et al. Involvement of napsin $A$ in the $C$ - and $\mathrm{N}$-terminal processing of surfactant protein $\mathrm{B}$ in type-II-pneumocytes of the human lung. J Biol Chem 2003;278:49006-49014.

14. Ueno $\mathrm{T}$, Linder $\mathrm{S}, \mathrm{Na} \mathrm{CL}$, et al. Processing of pulmonary surfactant protein B by napsin and cathepsin H. J Biol Chem 2004;279: 16178-16184.

15. Hirano T, Gong Y, Yoshida K, et al. Usefulness of TA02 (napsin A) to distinguish primary lung adenocarcinoma from metastatic lung adenocarcinoma. Lung Cancer 2003;41:155-162.

16. Ueno $\mathrm{T}$, Linder $\mathrm{S}$, Elmberger $\mathrm{G}$. Aspartic proteinase napsin is a useful marker for diagnosis of primary lung adenocarcinoma. $\mathrm{Br} \mathrm{J}$ Cancer 2003;88:1229-1233.

17. Dejmek A, Naucler $P$, Smedjeback A, et al. Napsin A (TA02) is a useful alternative to thyroid transcription factor-1 (TTF-1) for the identification of pulmonary adenocarcinoma cells in pleural effusions. Diagn Cytopathol 2007;35:493-497.

18. Hirano $T$, Auer G, Maeda $M$, et al. Human tissue distribution of TA02, which is homologous with a new type of aspartic proteinase, napsin A. Jpn J Cancer Res 2000;91:1015-1021.

19. Mori K, Kon Y, Konno A, et al. Cellular distribution of napsin (kidneyderived aspartic protease-like protein, KAP) mRNA in the kidney, lung and lymphatic organs of adult and developing mice. Arch Histol Cytol 2001;64:319-327. 
20. Ho SN, Hunt HD, Horton RM, et al. Site-directed mutagenesis by overlap extension using the polymerase chain reaction. Gene 1989;77:51-59.

21. Lin S, Phillips KS, Wilder MR, et al. Structural requirements for intracellular transport of pulmonary surfactant protein B (SP-B). Biochim Biophys Acta 1996;1312:177-185.

22. McCormack FX, Damodarasamy M, Elhalwagi BM. Deletion mapping of $\mathrm{N}$-terminal domains of surfactant protein $\mathrm{A}$. The $\mathrm{N}$-terminal segment is required for phospholipid aggregation and specific inhibition of surfactant secretion. J Biol Chem 1999;274: 3173-3181.

23. Holzinger A, Phillips KS, Weaver TE. Single-step purification/ solubilization of recombinant proteins: application to surfactant protein B. Biotechniques 1996:20:804-806, 808.

24. Graham FL, Smiley J, Russell WC, et al. Characteristics of a human cell line transformed by DNA from human adenovirus type 5. J Gen Virol 1977;36:59-74.

25. Schauer-Vukasinovic V, Bur D, Kitas $E$, et al. Purification and characterization of active recombinant human napsin $\mathrm{A}$. Eur J Biochem 2000;267:2573-2580.
26. Shen SS, Krishna B, Chirala R, et al. Kidney-specific cadherin, a specific marker for the distal portion of the nephron and related renal neoplasms. Mod Pathol 2005;18:933-940.

27. Okuzawa K, Franzen B, Lindholm J, et al. Characterization of gene expression in clinical lung cancer materials by two-dimensional polyacrylamide gel electrophoresis. Electrophoresis 1994;15:382-390.

28. Garcia M, Platet N, Liaudet E, et al. Biological and clinical significance of cathepsin D in breast cancer metastasis. Stem Cells 1996;14:642-650.

29. Berchem G, Glondu M, Gleizes $M$, et al. Cathepsin-D affects multiple tumor progression steps in vivo: proliferation, angiogenesis and apoptosis. Oncogene 2002;21:5951-5955.

30. Glondu M, Liaudet-Coopman E, Derocq D, et al. Down-regulation of cathepsin-D expression by antisense gene transfer inhibits tumor growth and experimental lung metastasis of human breast cancer cells. Oncogene 2002;21:5127-5134.

31. Tang J, Wong RN. Evolution in the structure and function of aspartic proteases. J Cell Biochem 1987;33:53-63.

32. Hsueh WA, Baxter JD. Human prorenin. Hypertension 1991;17:469-477.

33. Larsen LB, Boisen A, Petersen TE. Procathepsin D cannot autoactivate to cathepsin D at acid pH. FEBS Lett 1993:319:54-58. 